\title{
AS CONTRIBUIÇÕES DO ESTATUTO DE BENEFÍCIOS FISCAIS DE PORTUGAL PARA O APERFEIÇOAMENTO DA POLÍTICA FISCAL BRASILEIRA
}

\author{
Luiz Felipe da Fonseca Pereira ${ }^{1}$
}

\section{Resumo:}

A dinâmica atual exige por parte dos Estados repensarem suas políticas fiscais. Assim, o objeto deste trabalho é discutir as possíveis contribuições do estatuto de benefícios fiscais de Portugal para a política fiscal brasileira. Para isto, são apresentados o contexto físcal português e nacional, o estatuto, considerações doutrinarias, e o critério da caducidade dos benefícios no estatuto, posteriormente levanta-se outras considerações. O resultado possibilita concluir que o estatuto traz grandes contribuições para um possível aperfeiçoamento da política fiscal brasileira, porém ajustes devem ser feitos para realidade nacional, pois se deve respeitar os preceitos constitucionais e a proteção da segurança jurídica.

Palavras-chaves: Benefícios Fiscais; Brasil; Portugal; Caducidade; Política Fiscal.

\section{THE CONTRIBUTIONS OF THE PORTUGAL FISCAL BENEFIT STATUTE TO IMPROVEMENT BRAZILIAN FISCAL POLICY}

\begin{abstract}
Current dynamics require states to rethink their fiscal policies. Thus, the object of this paper is to discuss the contributions of the Portuguese tax benefits statute to the Brazilian fiscal policy. For this, the Portuguese and national tax context, the statute, doctrinal considerations, and the criterion of forfeiture of benefits are presented, and other considerations are raised later. The result makes it possible to conclude that the statute makes contributions to a improvement of the Brazilian fiscal policy, but adjustments must be made to the national reality, as the constitutional precepts and the protection of legal certainty must be respected.
\end{abstract}

Key-Words: Fiscal Statute; Brazil; Portugal; Forfeiture; Fiscal Policy.

\section{INTRODUÇÃO}

Como qualquer área de atuação do direito, na atualidade, acabam por sofrer mudanças, visto que a sociedade mudou junto com o desenvolvimento impressionante da população mundial no último século, o mesmo ocorreu com as estruturas estatais necessárias para garantir o bom funcionamento do estado, bem como o fornecimento de serviços à

\footnotetext{
${ }^{1}$ Advogado, mestrando em Direito, na área de concentração em Direito Tributário e Direitos Humanos na Universidade Federal do Pará, Graduando em Direito pela Universidade Federal do Pará com período sanduíche na Faculdade de Direito da Universidade de Coimbra - Portugal (2016). Tem experiência na área de Direito, com ênfase em Direito Econômico, Direito Tributário e Direito Financeiro.
} 
população, assim o direito administrativo, financeiro, tributário e econômico vem sofrendo mutações para se adequar as mudanças da realidade social.

O Sistema Fiscal, genericamente, tem o intuito de gerar um nível de receita que permita o financiamento do Estado, ou seja, o financiamento dos gastos da Administração pública, nomeadamente aqueles que se prendem especificamente como os serviços de saúde, a educação, as prestações sociais, a segurança dos cidadãos e os diretamente ligados a estes como o gasto com pessoal na máquina pública etc.

A Comissão econômica para América Latina e Caribe da ONU (CEPAL, 2018), bem como a Asset Management J.P. Morgan (2019), divulgaram estudos no qual consta uma aceleração significativa no endividamento dos países da região Ásia-pacífico e da América Latina em comparação com as dívidas da Europa e América do Norte, desde o ano de 2009. A América Latina obteve um aumento de 3,6\% da sua dívida em relação ao PIB, mostrando que a progressão da dívida tem sido superior ao crescimento do PIB, a mesma pesquisa ressalta que países como Portugal e Itália continuam por ter uma dívida pública significativa.

Analisando também as estatísticas recentes da OCDE (2014) mostram que os custos para os cofres dos Estados são relativamente elevados acerca de benefícios fiscais, porém alguns países não alcançam resultados significativos com a concessão desses benefícios.

Por outro lado, outros países desenvolvidos, concedem especiais incentivos ou benefícios somente em casos excepcionais, nos âmbitos de atividades industriais de alta cadeia produtiva ou de Pesquisa e Desenvolvimento em inovação tecnológica - P\&D, e em áreas de relevante interesse econômico ou social.

Muitos desses Estados estão melhorando suas políticas de benefícios, analisando as boas práticas de outros países, através do direito comparado, todavia é interessante ressaltar que em se tratando de benefícios fiscais, deve-se entender primeiro as diferenças e similaridades de concepções entre o ordenamento nacional e o ordenamento alienígena, e outros aspectos essenciais para o entendimento do tema, visto que parte da doutrina brasileira e lusitana considera benefícios fiscais como benefícios tributários ou incentivos, ou viceversa, ressalta-se que os benefícios fiscais são gênero e os benefícios tributários espécie.

No Brasil a situação é calamitosa com a dívida pública podendo ultrapassar em $80 \%$ do PIB em 2020 (BRASIL, 2018, p. 29), e uma concessão demasiadamente alta de benefícios fiscais chegando na casa de $\mathrm{R} \$ 354,7$ bilhões de reais, o que representou 5,4\% do PIB em 
2017, sendo R \$ 270,4 bilhões por meio de gastos tributários e $\mathrm{R} \$ 84,3$ bilhões via benefícios financeiros e creditícios (MINISTERIO DA ECONOMIA, 2018, p. 4).

À luz desta temática, o presente trabalho tem o escopo de avaliar as contribuições do Estatuto de Benefícios Fiscais de Portugal que podem auxiliar no aperfeiçoamento da política fiscal brasileira, contribuindo com critérios mais objetivos e maior controle na sua concessão. O trabalho abordará: 1) o contexto fiscal português que levou a necessidade da criação do código especial sobre o tema e a realidade brasileira, 2) Definição de benefícios fiscais no Brasil, 3) o Estatuto de Benefícios Fiscais português e suas particularidades, 4) as contribuições do referido estatuto para o aperfeiçoamento da política fiscal brasileira.

\section{CONTEXTO DO SISTEMA FISCAL PORTUGUÊS E O BRASILEIRO}

Na Atualidade, pensar no sistema fiscal português faz-se necessário pensar na União Europeia - UE, no qual faz parte, onde existe órgãos como o Parlamento Europeu que é composto por representantes de cada Estado Membro, a nível de eurodeputados, que tem força para vincular o governo do seu respectivo Estado as decisões tomadas neste órgão, que interferem na decisão do orçamento, e junto com o Parlamento há o Conselho da União Europeia, em que ambos possuem competência legislativa e orçamental, tanto para assuntos econômicos e/ou monetários como também em assuntos diversos dos seus Estados membros, no que tange as diretrizes Europeias no qual devem seguir, sendo estas econômicas e políticas.

Antes de ano de 2012, Portugal ainda se encontrava com pendências no seu sistema Fiscal em face das diretrizes da União Europeia, este ano foi considerado um divisor de águas no sistema fiscal português, pois de acordo com objetivos traçados no Documento de Estratégia Orçamental publicado em abril de 2012 pelo Ministério das Finanças e em consonância com as medidas aprovadas para a área fiscal no Memorando de Entendimento celebrado com a União Europeia, Banco Central Europeu - BCE e Fundo Monetário Internacional - FMI em maio de 2011, entraram em vigor, em 01 de Janeiro de 2012, diversas alterações ao regime fiscal constantes da Lei 64-B/2011 de 30 de Dezembro - Orçamento de Estado para 2012 e do Orçamento Retificativo, Lei n. ${ }^{\circ} 20$ de 14 de Maio de 2012, bem como alterações no Estatuto de Benefícios Fiscais.

Este foi o caminho encontrado para que Portugal atenda as exigências europeias e também para aplicar as medidas de austeridade impostas pelo Banco Central Europeu em 
virtude da crise, como dispõe o relatório do Banco de Portugal (2013), e desta forma conseguir empréstimo de 78 bilhões de euros, e para tal teve que tomar medidas como aumento de impostos, cortes nos salários do funcionalismo público e nas aposentadorias, aumento das taxas para utilização dos serviços de saúde, redução em investimentos na educação, privatizações dentre outras medidas (BANCO DE PORTUGAL, 2013, p. 3-6).

Em face das alterações surgidas na mudança de parâmetros do sistema fiscal português é interessante ressaltar que as alterações foram com intuito de aplicar as medidas de austeridade e assim causando um aumento da tributação em Portugal, isto é claro ao analisar o Imposto Sobre o Rendimento das Pessoas Singulares - IRS, no qual no seu último escalão houve um aumento de $2,5 \%$, subindo para $49 \%$. No que tange os impostos especiais de consumo, houve a criação de um imposto sobre a eletricidade, e um significativo aumento na alíquota do imposto sobre bebidas, tabaco, petróleo e gasóleo (Diesel) de aquecimento (AICEP, 2012, p. 6-7).

Isto também atingiu a concessão de benefícios fiscais, visto que na atual crise o Estado português não poderia conceder os mesmos benefícios tanto a pessoas coletivas (pessoa jurídica) quanto singulares (pessoa física), mas sim dando prioridade a questões de relevante interesse nacional, um exemplo disto é o fato da busca em 2015 da Assembleia da República Portuguesa em aumentar o salário mínimo em Portugal, todavia Portugal foi aconselhado pela OCDE a evita-lo e buscar outra via, pois acarretaria em aumento dos custos com mão de obra e poderia gerar aumento de desemprego, e em vez disto, conceder benefícios fiscais aos que ganham menos no país (OCDE, 2015, 2017).

Quanto a realidade brasileira é latente que a carga tributária brasileira é demasiadamente elevada, tanto para pessoa jurídica como para pessoa física, interferindo diretamente no consumo. As obrigações tributarias para os empresários, hoje no Brasil, deixou de ser uma questão cotidiana, e tornou-se estratégico para as empresas de todos os portes.

O Instituto Brasileiro de Planejamento e Tributação - IBPT (2015), em um estudo, revelou que o Brasil possui um dos sistemas tributários mais complexos do mundo, com uma grande quantidade de lei, decretos, regulamentos e normas sendo alteradas constantemente, por este motivo demanda-se mais gastos das empresas para o planejamento tributário, e ao analisarmos o Estado, no contexto dos benefícios fiscais, estes representam despesa pública 
fiscal, ocasionando a tributação plena e muitas vezes excessiva de quem não é coberto por estes benefícios.

Segundo o mesmo instituto, o aumento da carga tributária no país vem ocorrendo desde os anos 40, quando houve a possibilidade desta análise, através da elaboração da Sistemática de Contas Nacionais do Brasil. Naquele momento histórico os tributos eram mais de $14 \%$ do PIB, foi dos $15 \%$ aos $16 \%$ em 1950 e posteriormente passou de $18 \%$ aos $19 \%$, em 1990 atingiu 29,91\%, batendo um recorde, entre os anos 1991 a 1993 e voltou a faixa de $25 \%$.

Se analisarmos os valores médios pagos pelos brasileiros de 1993 a 2001, houve um aumento de 288,75\%, pois em 1993 pagava-se $\mathrm{R} \$ 700,51$ (setecentos reais e cinquenta e um centavos) de tributos, em 1999 era de $\mathrm{R} \$$ 1.815,13 (mil oitocentos e quinze reais e treze centavos), aumentando para $\mathrm{R} \$ 2.361,08$ (dois mil trezentos e sessenta e um reais e oito centavos) em 2001, no ano de 2002 atingiu R \$ 2.723,26 (dois mil setecentos e vinte e três reais e vinte e seis centavos), vale ressaltar que no ano de 2002 a renda per capita da população brasileira era de $\mathrm{R} \$ 7.470,86$, assim cada brasileiro trabalhava 4 meses e 13 dias no ano de 2002 para o pagamento de tributos.

No ano de 2017 foram necessários 152 dias de trabalho para pagar os tributos o que é equivalente a 5 meses (IBPT, 2017), uma pequena comparação com outros países, na Alemanha são 139 dias, na Bélgica 140 dias, assim o Brasil está próximo da Noruega que são 157 dias, mas diferente do país nórdico, o Brasil não possui um dos melhores IDH do mundo, muito menos a mesma qualidade de vida e de serviços públicos.

O IBPT em seu estudo "Carga Tributária/PIB x IDH - Cálculo do Índice de Retorno de Bem Estar à Sociedade - IRBES” (2019), avaliaram os 30 países com a maior carga tributária do mundo e o Brasil tem o pior retorno à população em face dos tributos arrecadados, o que nos mostra que o Brasil precisa com urgência de uma mudança na política fiscal, para que atenda às necessidades sociais, bem como faça o país crescer principalmente em tempos de crise e do aumento da taxa de juros do Federal Reserve - FED (Banco Central americano), o que pode retirar muitos investimentos do país.

\section{ESTATUTO DOS BENEFÍCIOS FISCAIS - EBF DE PORTUGAL}

\section{1 GENERALIDADES}

Os aspectos de concessão e revogação e demais assuntos inerentes aos benefícios fiscais em Portugal encontram-se inseridos no Estatuto dos Benefícios Fiscais - EBF aprovado 
pelo Decreto-Lei n. ${ }^{\circ}$ 215/89 e nos códigos dos diferentes impostos e em legislação avulsa para o determinado fim.

Dando cumprimento ao disposto no Memorando de Entendimento, o Governo português procedeu ao congelamento ou mesmo à revogação de alguns dos benefícios fiscais que se encontravam em vigor em 31 de dezembro de 2011.

O EBF define o enquadramento legal e os princípios fiscais a que deve obedecer a criação das situações de benefício, as regras da sua atribuição e reconhecimento administrativo e o elenco desses mesmos benefícios, com um duplo objetivo, garantir maior estabilidade aos diplomas reguladores das espécies tributárias e fiscais, e conferir um carácter sistemático ao conjunto dos benefícios fiscais, facilitando assim a fiscalização e controle e dando clareza ao contribuinte.

Segundo João Ricardo Catarino (2014, p. 476-478), professor da Universidade de Lisboa, as três principais motivações no qual se norteia o estatuto e a política de benefícios fiscais são:

a) Atribuição aos Benefícios Fiscais de um carácter obrigatoriamente excepcional, só devendo ser concedidos em casos de reconhecido interesse público;

b) Estabilidade: de modo a garantir aos contribuintes uma situação clara e segura;

c) Moderação: dado que as receitas são postas em causa com a concessão de benefícios, principalmente quando o país tem de reduzir o peso do défice público;

\subsection{BENEFÍCIOS FISCAIS SEGUNDO EBF E CONSIDERAÇÕES DOUTRINÁRIAS}

É notório que a política fiscal tem um impacto importante no crescimento econômico. A economista portuguesa Conceição Castro (2006) realizou vários estudos analisando as relações entre a política fiscal e o crescimento econômico a longo prazo, por sua vez baseou-se em vários modelos de teoria de crescimento econômico, buscando aferir essa correlação entre a política fiscal e crescimento econômico, constatou que a política fiscal exerce influência na decisão de investir em determinados setores o que consequentemente afeta o crescimento econômico, por isso o uso de instrumentos fiscais é de fundamental importância como mecanismo de equilibrar ciclos econômicos.

Os Benefícios Fiscais segundo o EBF, são medidas de caráter excepcional com finalidades extrafiscais como assim diz o art. 2 do EBF, artigo este que está de acordo com o entendimento da doutrina portuguesa sobre o tema: 
Artigo 1. ${ }^{\circ}$

Âmbito de aplicação

As disposições da parte i do presente Estatuto aplicam-se aos benefícios fiscais nele previstos, sendo extensivas aos restantes benefícios fiscais, com as necessárias adaptações, sendo caso disso.

Artigo 2. ${ }^{\circ}$

Conceito de benefício fiscal e de despesa fiscal e respectivo controlo

1 - Consideram-se benefícios fiscais as medidas de carácter excepcional instituídas para tutela de interesses públicos extrafiscais relevantes que sejam superiores aos da própria tributação que impedem.

[...] [grifo nosso]

Com entendimento presente no EBF e da doutrina portuguesa, os benefícios fiscais, são medidas de carácter excepcional, com motivações extrafiscais de interesse superior à tributação estabelecida, e assim deverá vigorar apenas enquanto esse interesse se mantiver presente, evitando-se a sobrecarga fiscal de entidades sujeitas a tributação plena, para compensar a perda de receita associada. Os benefícios fiscais podem ter várias facetas, como por exemplo, de caráter social, de estímulo econômico a determinadas entidades, regiões ou setores da economia. Manuel Pereira (1998) conclui por sua vez que são três os requisitos do benefício fiscal: 1) É uma derrogação às regras de tributação; 2) Constitui uma vantagem para os contribuintes; 3) Tem que ter um escopo econômico ou social relevante.

Vale ressaltar também que o próprio Estatuto define os benefícios fiscais como despesas fiscais no art. 2 do texto legal, pois para o contribuinte é um benefício, todavia ao Estado é uma despesa:

\section{Artigo 2. ${ }^{\circ}$}

Conceito de benefício fiscal e de despesa fiscal e respectivo controlo $[\ldots]$

3 - Os benefícios fiscais são considerados despesas fiscais, as quais podem ser previstas no Orçamento do Estado ou em documento anexo e, sendo caso disso, nos orçamentos das Regiões Autónomas e das autarquias locais.

4 -Para efeitos de controlo da despesa fiscal inerente aos benefícios fiscais concedidos, pode ser exigida aos interessados a declaração dos rendimentos isentos auferidos, salvo tratando-se de benefícios fiscais genéricos e automáticos, casos em que podem os serviços fiscais obter os elementos necessários ao cálculo global do imposto que seria devido.

\section{[...] [grifo nosso]}

O artigo supracitado não só definiu que os benefícios fiscais devem ser tratados como despesas fiscais como apresentou um dos mecanismos de controle para evitar um total descontrole da despesa pública, prejudicando assim a boa saúde econômica do Estado, bem como a violação de regras dos tratados da União Europeia, no caso o "Pacto Euro Mais" e a 
"Estratégia Europa 2020" mecanismo que visam um maior controle orçamental e físcal dos países da zona euro, bem como o controle do déficit e da dívida pública (PARLAMENTO EUROPEU, 2019).

O reforço ao controle das despesas públicas começou a ser implementado no intuito de resolver problemas de ordem quantitativa e qualitativa. Percebe-se que a herança do pensamento liberal vem se alterando e desta forma um maior interesse vem se dando a despesa pública, pois "se reconheceu que não bastava confinar o rédito público dentro de apertados limites de legalidade e aprovação parlamentar para garantir os interesses patrimoniais dos cidadãos e a qualidade da despesa pública" (CATARINO, 2014, p.399).

Barro e Sala-i-Martin (1990) ao estudarem a função da política fiscal em modelos econômicos endógenos, concluíram que se o retorno social sobre um investimento é maior que o retorno privado, a política fiscal que incentivem investimentos pode aumentar o desenvolvimento econômico e social. Os benefícios fiscais ao investimento não serão apelativos ao setor privado se a taxa de retorno sobre o investimento for igual a taxa social, ou seja, a grande preocupação é com os benefícios terem um retorno social igual ou maior a taxa de retorno de investimento, para assim evitar prejuízos ao Estado bem como ao setor privado.

Esta afirmação acima, é ratificada quando se analisa os relatórios da OCDE (2012, 2015, 2017) e as informações apresentadas pelo Professor Guilherme Waldemar D’Oliveira Martins no livro A despesa fiscal e o Orçamento do Estado no ordenamento jurídico português (2004), no qual tratam mais delicadamente a situação fiscal portuguesa.

\subsection{CADUCIDADE DOS BENEFÍCIOS FISCAIS}

O interesse de se conceder um benefício deve ser claramente superior ao de tributar, este benefício deve ser regulamente avaliado, para saber se os objetivos estão sendo alcançados, em virtude disto também é necessário a fixação de um prazo, para que a termino deste, os benefícios passem por avaliação, e sejam extintos por não alcançarem os objetivos pretendidos, suspensos para regularização de alguma situação prejudicial ao alcance do respectivo escopo, ou se é passível de renovação.

No EBF a caducidade dos benefícios fiscais é tratada no art. $3^{\circ}$ do Estatuto, no qual estabelece o prazo-regra de 5 anos, podendo ser diferente a depender do que estiver disposto em contrário no Próprio Estatuto:

Artigo $3 .^{\circ}$ 
Caducidade dos benefícios fiscais

1 - As normas que consagram os benefícios fiscais constantes das partes ii e iii do presente Estatuto vigoram durante um período de cinco anos, salvo quando disponham em contrário. 2 - São mantidos os benefícios fiscais cujo direito tenha sido adquirido durante a vigência das normas que os consagram, sem prejuízo de disposição legal

em

contrário.

3 - $O$ disposto no n. 1 não se aplica aos benefícios fiscais constantes dos artigos $16 .^{\circ}, 17 .^{\circ}, 18 .^{\circ}, 21 .^{\circ}, 22 . .^{\circ}, 23 .^{\circ}, 24 .^{\circ}, 32 . .^{\circ}, 44 .^{\circ}, 60 .^{\circ}$ e $66 .^{\circ}$-A, bem como ao capítulo $v$ da parte ii do presente Estatuto. (Redacção dada pelo artigo $144 .^{\circ}$ da Lei n. ${ }^{\circ}$ 64-B/2011, de 30 de dezembro de 2011)

[...] [grifo nosso]

Assim em algumas hipóteses a regra geral de 5 anos de vigência de um benefício é afastada por motivos de interesse maior, como por exemplo os benefícios relativos a fundo de pensões, contribuições das entidades patronais para regimes de segurança social, fundos de investimento, fundos de capital de risco, fundos de investimento imobiliário em recursos florestais e proteção do meio ambiente, bem como benefícios à reestruturação empresarial e às cooperativas e ainda os benefícios fiscais em razão de relações internacionais como tratados de não dupla tributação.

Assim o art. 16 do EBF estabelece que os fundos de pensões que existam de acordo com a legislação portuguesa, ficam isentos do Imposto sobre Rendimentos das Pessoas Coletivas - IRC, pelo tempo que existir o fundo, em consonância com o art. 9 do Decreto-lei $\mathrm{n}^{\circ}$ 442-B de 30 de novembro de 1988, em total conformidade com o que estar estabelecido no artigo supracitado do EBF, bem como estão isentas de imposto municipal sobre transmissões onerosas de imóveis - IMT, os fundos de pensões e equiparáveis, constituídos também em total acordo com a legislação portuguesa.

Os fundos de pensão que se encontram de acordo com a legislação portuguesa, o benefício será concedido pela Autoridade Tributaria e Aduaneira - $\mathrm{AT}^{2}$ em conformidade com o disposto no Decreto Lei 118/2011 (Lei Orgânica da Autoridade Tributaria e Aduaneira), que por sua vez também tomará as medidas cabíveis de fiscalização, a fim que os preceitos legais sejam respeitados e que o sujeito beneficiado os respeite em sua totalidade.

Vale ressaltar que estes fundos de pensões também devem estar em total acordo com os regulamentos da União Europeia sobre o tema, através dos regulamentos da Autoridade Europeia de Seguros e Pensões Profissionais - AEAPP, autoridade essa que configura-se como uma agencia reguladora acerca dos Seguros e Pensões Profissionais na União Europeia,

\footnotetext{
${ }^{2}$ a Autoridade Aduaneira - AT em Portugal equivale a Receita Federal brasileira.
} 
é órgão integrante Comitê Europeu de Risco Sistêmico - CERS, presidido pelo Banco Central Europeu - BCE, em consonância com o projeto econômico e político europeu denominado: Sistema Europeu de Supervisão Financeira - SESF (COUTEAU, 2013, p. 123), criado após a crise de 2010 dos Estados europeus, com o objetivo de uma fiscalização financeira constante de toda a comunidade.

No caso especial de benefícios referentes ao Imposto Municipal sobre Imóveis - IMI e o Imposto Municipal sobre as transmissões onerosas de bens Imóveis - IMT, a competência recai sobre a própria Câmara Municipal ou através dos serviços de entidade intermunicipal do qual integram, como estabelece o art. 17 da Lei 73/2013 que regula o regime financeiro das Autarquias Locais e Entidade Intermunicipais.

As hipóteses de benefícios fiscais, mais precisamente os benefícios tributários, isto é, renúncia de receitas, estão previstos quase em sua totalidade do EBF, que elenca todas as regras gerais a que deve obedecer a criação das situações de benefícios, as regras da sua atribuição e reconhecimento administrativo e o elenco desses mesmo benefícios em muitos casos (TCP, 2014).

Os "pormenores”, lê-se critérios mais específicos, para concessão destas renúncias de receitas devem vir dispostas na lei específica de cada um dos tributos ou em leis que estabelecerem regimes fiscais especiais. Assim o EBF estabelece as hipóteses gerais para concessão dos Benefícios, que deveram ser respeitadas e vir no corpo legal de lei específica (GARCIA, 2014, p. 15). O Objetivo com o EBF é garantir maior estabilidade aos diplomas reguladores das espécies tributárias, como também conferir um caráter mais sistemático ao conjunto dos benefícios fiscais (TCP, 2014, p. 16).

Percebe-se que nos casos divergentes da regra de 5 anos para caducidade no presente Estatuto, deverão ser analisados os casos concretos e as necessidades da situação em tela, assim, preenchendo os requisitos, os fundos de pensão enquanto existirem terão os benefícios previsto em lei, como os fundos de investimentos em áreas estratégicas para economia, eles recebem os benefícios fiscais no seu tempo de vigência, podendo os mesmos serem prorrogados.

\section{AS CONTRIBUIÇÕES DO ESTATUTO DE BENEFÍCIOS FISCAIS DE PORTUGAL PARA APERFEIÇOAMENTO DA POLÍTICA FISCAL BRASILEIRA}


O estatuto de benefícios fiscais de Portugal serve de diploma regulador para uma melhor concessão das renúncias de receitas, evitando assim desvirtuação dos objetivos pretendidos com a política fiscal de concessão bem como um mecanismo de impedimento de desperdício de recurso público que poderia ser mais bem realocado pelo próprio Estado.

Num primeiro momento verifica-se que no brasil o artigo 14 da Lei de Responsabilidade Fiscal, estabelece como critérios para concessão de renúncia de receitas somente:

Art. 14. A concessão ou ampliação de incentivo ou benefício de natureza tributária da qual decorra renúncia de receita deverá estar acompanhada de estimativa do impacto orçamentário-financeiro no exercício em que deva iniciar sua vigência e nos dois seguintes, atender ao disposto na lei de diretrizes orçamentárias e a pelo menos uma das seguintes condições:

I - demonstração pelo proponente de que a renúncia foi considerada na estimativa de receita da lei orçamentária, na forma do art. 12, e de que não afetará as metas de resultados fiscais previstas no anexo próprio da lei de diretrizes orçamentárias;

II - estar acompanhada de medidas de compensação, no período mencionado no caput, por meio do aumento de receita, proveniente da elevação de alíquotas, ampliação da base de cálculo, majoração ou criação de tributo ou contribuição. [grifo nosso]

Todavia não há a necessidade da presença destes dois critérios de forma simultânea, mas sim ocorrendo de forma alternativa, o que coloca em risco um maior controle da disciplina da concessão. Por outro lado, o diploma português na parte geral ou parte I, além de estabelecer que deve constar no orçamento do Estado o beneficio fiscal, por força do item 3 do artigo $2^{\circ}$ do EBF, ainda estabelece a caducidade, o prazo, desses benefícios que será por via de regra de 5 (cinco) anos, salvo benefícios de setores estratégicos que deveram ter um prazo específico previsto no artigo $3^{\circ}$, item 1 , mas não se ausentando das outras obrigações como a previsão no orçamento público. Podendo os benefícios serem renovados por iguais períodos caso ainda exista os fundamentos de sua concessão.

$\mathrm{O}$ artigo $6^{\circ}$, item 2 prolata que a formulação de benefícios fiscais: "deve obedecer o princípio da igualdade, de modo a não falsear ou ameaçar falsear a concorrência”, preocupação ausente na legislação brasileira sobre o cuidado com a livre concorrência e os impactos das renuncias de receitas concedidas de forma quase discriminada pelo Estado brasileiro, o que exige um esforço muito maior de seus órgão na análise desta perspectiva econômica como o Conselho Administrativo de Defesa Econômica - CADE.

$\mathrm{O}$ artigo 14 do EBF estabelece critérios gerais de extinção dos benefícios fiscais, em especial o item 4 do referido artigo estabelece que: 
4 - O acto administrativo que conceda um benefício fiscal não é revogável, nem pode rescindir-se o respectivo acordo de concessão, ou ainda diminuir-se, por acto unilateral da administração tributária, os direitos adquiridos, salvo se houver inobservância imputável ao beneficiário das obrigações impostas, ou se o benefício tiver sido indevidamente concedido, caso em que aquele acto pode ser revogado.

Isto é, a proibição de revogar por ato unilateral da administração tributária a concessão de benefício é um mecanismo de proteção do contribuinte, evitando que por interesses ou causas diversas, veja seus benefícios serem extirpados de forma unilateral, cabendo a extinção na falha do beneficiário de suas obrigações pecuniárias e assessorias.

O diploma legal português na sua parte II, Estabelece as regras de concessão de benefícios fiscais de caráter estrutural, isto é benefícios fiscais permanentes na política fiscal portuguesa, divididos por setores estratégicos, vale citar a exemplo, que: 1) O capítulo I, trata dos benefícios fiscais de natureza social; 2) $\mathrm{O}$ capítulo II, os benefícios à poupança; 3) $\mathrm{O}$ capítulo VII, os benefícios relativos a bens imóveis e 4) O capítulo XI aos benefícios às cooperativas, cada um deles com suas especificidades, criando uma unidade na política fiscal nacional.

Diferentemente do cenário brasileiro que devido a multiplicidade de regras fiscais entre os estados, acaba por gerar uma guerra fiscal, em especial se tratando de ICMS, o que é nocivo ao ecossistema empreendedor ${ }^{3}$ nacional e obstrui o desenvolvimento econômico e social, onde os estados mais pobres (região norte e nordeste) tem menos poder de "barganha" em face dos estados mais ricos, no caso a região centro-sul, o que diverge do objetivo fundamental da república federativa do brasil no artigo $3^{\circ}, \mathrm{IV}$ da $\mathrm{CF} / 88$, que é reduzir as desigualdades socias e regionais, pois o atual modelo ratifica o status quo.

$\mathrm{O}$ estatuto de benefícios fiscais traz também toda a estrutura do Regime Fiscal do Apoio ao investimento (RFAI) e do Sistema de Incentivos Fiscais à Inovação e Desenvolvimento Empresarial II (SIFIDE II), pois o primeiro SIFIDE tinha entraves fiscais perigosos que poderiam comprometer o alcance dos objetivos, estes dois mecanismo que exigem contrapartidas do setor privado para recebimento dos benefícios, mostraram-se excelentes instrumentos para estimulo à inovação e investimento em face da indústria de ponta, e assim, Portugal tornou-se um dos principais celeiros de startups da Europa, uma das

\footnotetext{
${ }^{3} \mathrm{O}$ ecossistema empreendedor pressupõe a ação de atores interdependentes (consumidor, empresas, Estado etc.), tem caráter evolutivo e é o ambiente necessário para o surgimento de empresas de alto crescimento e inovação, em especial a tecnológica, possuindo 6 domínios: políticas públicas, capital financeiro, cultura, suporte (capital físico, órgãos de classe etc.), capital humano e mercados (ISENBERG, 2011).
} 
estratégias de enfrentamento da crise econômica (AGÊNCIA NACIONAL DE INOVAÇÃO DE PORTUGAL, 2019).

\section{CONCLUSÃO}

O problema das renúncias de receita é de longa data no Brasil, pois o que para o Estado é renuncia ao contribuinte é benefício. Portugal por diversos fatores econômicos, políticos e sociais buscou uma forma de contornar o problema que passava, o qual o Brasil ainda se encontra sem resposta e sem diretriz.

No primeiro momento buscou-se apresentar brevemente a importância da temática na atualidade e como a tributação e a sua não tributação causa impactos fortes na economia e na vida dos indivíduos em sociedade, apresentou-se também o atual contexto fiscal português e brasileiro e as preocupações atuais sobre a referida temática.

Em seguida, apresentou-se o Estatuto de benefícios Fiscais e suas generalidades, bem como o conceito de benefícios fiscais e considerações doutrinarias da academia portuguesa, e uma atenção especial a caducidade dos benefícios fiscais, que em regra geral são de 5 anos, salvo disposição em contrário presente no próprio diploma legal.

Posteriormente, apresentaram-se as contribuições do Estatuto de Benefícios Fiscais, como: 1) o prazo em regra geral de 5 anos no artigo $3^{\circ}$, item 1 ; 2) o artigo 14 , item 4 , que estabelece critério de segurança ao contribuinte beneficiário contra ato unilateral estatal extintivo do benefício fiscal; 3) a proteção da concorrência na formulação de benefícios fiscais por força do artigo 6 , item 2 ; 4) o objetivo de criar uma unidade da política fiscal em todo território português evitando assim uma possível guerra fiscal entre as regiões da parte continental do país unitário, bem como das regiões insulares e; 5) e o estabelecimento de dois mecanismo de incentivo a inovação tecnológica para fazer frente a crise financeira que assola o país.

No Brasil, porém a ausência de legislação especifica estabelecendo diretrizes e critérios objetivos na concessão, manutenção e extinção, causa prejuízos ao Estado, pois o estado beneficia setores e/ou áreas sem a utilização de devidos critérios de avaliação, o que acaba por traduzir em desperdício de recursos, recursos esses que poderiam ser melhor empregados na efetivação de obrigações chaves do governo, como educação, saúde e segurança. Para a econômica nacional, o mercado e o setor privado há um duplo dano, primeiro pode gerar distorções na concorrência, prejudicando em especial pequenas e medias 
empresas que são mais sensíveis as alterações econômicas, em segundo porque como estas renúncias de receita devem ser compensadas como ordena a LRF, outros setores estarão sobrecarregados com excesso de tributação.

E no fim desta escala quem receberá todo o impacto negativo será a sociedade, primeiro porque o Estado renunciou a receita que poderia fazer frente as necessidades sociais, segundo porque estes benefícios que foram ao setor privado não alcançaram seus objetivos de geração de maior número de emprego e por consequência renda, bem como a contribuição para o desenvolvimento econômico e social do país, demonstração clara disto é o montante de benefícios fiscais concedidos pelo Estado brasileiro. O Brasil é $9^{\circ}$ país que mais concede benefícios fiscais à inovação, mais do que países como Canadá e Holanda, porém continua com resultados francos no seu desempenho inovativo e econômico, sendo $64^{\mathrm{a}}$ posição no índice internacional de inovação (WIPO et al., 2018)

\section{REFERÊNCIA BIBLIOGRÁFICA}

AGÊNCIA DE NACIONAL DE INOVAÇÃO DE PORTUGAL. Ranking e Indicadores. Disponível em: <https://www.ani.pt/pt/avaliação-e-monitoracao/monitoração/ranking-eindicadores/>. Acesso em abril de 2019.

AICEP, Agência para o Investimento e Comércio Externo de Portugal. Portugal Sistema Fiscal. Lisboa: AICEP, 2012Portugal Sistema Fiscal. Lisboa: AICEP, 2012, p. 6-7.

BARRO, Robert j. e SALA-I-MARTIN, Xavier. Public Finance in Models of Economic Growth. Disponível em: <http://www.nber.org/papers/w3362>. Acesso em: 19 maio 2019.

BRASIL. Constituição (1988). Constituição da República Federativa do Brasil: promulgada em 05 de outubro de 1988. Disponível em: <http://www.planalto.gov.br/ccivil_03/Constituicao/Constituicao.htm>. Acesso em: 14 fevereiro 2019.

BRASIL. Lei Complementar $\mathbf{n}^{\mathbf{0}}$ 101, de 04 de maio de 2000. Estabelece normas de finanças públicas voltadas para a responsabilidade na gestão fiscal e dá outras providências. Disponível em: <http://www.planalto.gov.br/ccivil_03/leis/LCP/Lcp101.htm>. Acesso em: 20 maio 2019.

BRASIL. Presidente (2016-2018: Michel Temer). Proposta da Lei Orçamentaria Anual para 2019. Brasília, 2018.

CASTRO, Conceição. Política Fiscal e Crescimento Económico. Revista de Estudos Politécnicos, Cidade do Porto, Vol III, n. 5/6, 087-118, ISSN: 1645-9911, 2006.

CATARINO, João Ricardo. Finanças Públicas e Direito Financeiro. $2^{\mathrm{a}}$ ed. Coimbra: Almedina, 2014. 
CEPAL. The Preliminary Overview of the Economies of Latin America and the Caribbean. Santiago: United Nations, 2018.

COUTEAU, Armelle Renaut. L'Essentiel de la Gouvernance Économique et Monétaire de la Zone Euro. Paris: Gualino. 2013.

GARCIA, Adelaide et al..Estatuto de Benefícios Fiscais 2014 - Anotado \& Comentado. $1^{\text {a }}$ ed. Porto: Lexit, 2014.

IBPT. Carga Tributária/PIB x IDH - Cálculo do Índice de Retorno de Bem-Estar à Sociedade - IRBES. Curitiba: IBPT, 2019.

IBPT. Estudo Sobre os Dias Trabalhados para Pagar Tributos em 2017. Curitiba: IBPT, 2017.

IBPT. Evolução da Carga Tributária Brasileira. São Paulo: IBPT, 2015.

ISENBERG, D. J. The Entrepreneurship Ecosystem Strategy as a New Paradigm for Economic Policy: Principles for Cultivating Entrepreneurship. Dublin: Institute ofInternational European Affairs, 2011.

MARTINS, Guilherme Waldemar D'Oliveira. A despesa fiscal e o orçamento do Estado no ordenamento jurídico português. Coimbra: Editora Almedina, 2004.

MINISTÉRIO DA ECONOMIA DO BRASIL. Secretaria de Acompanhamento Fiscal, Energia e loteria - SEFEL. $2^{\circ}$ Orçamento de Subsídios da União: Relatório do Governo Federal sobre os gastos tributários e benefícios creditícios e financeiros no período de 2003 a 2017. Brasília, 2018.

MINISTÉRIO DAS FINANÇAS DE PORTUGAL. Documento de Estratégia Orçamental: 2012-2016. Lisboa, 2012.

MORGAN, J. P.. Market Insights: América Latina. New York, 2019

OCDE. Relatórios Econômicos da OCDE: Portugal. Paris, 2017

OCDE. Skills Strategy Diagnostic Report: Portugal 2015. Paris, 2015

OCDE. The Effectiveness of Public in Portugal \& la Budgétisation Axée Sur la Performance Dans Les Pays de L'ODCE, Economics Department, working papers n $^{\circ} 349$, Paris: ODCE, 2012.

OCDE. The Taxation of Fringe Benefits. Paris: ODCE, 2014.

ODCE. The Taxation of Fringe Benefits. Paris: ODCE, 2014.

PARLAMENTO EUROPEU. O quadro da EU para as políticas orçamentarias. Bruxelas, 2019.

PEREIRA, Manuel Coutinho. Efeitos Macroeconômicos das Alterações da Legislação Fiscal em Portugal - Boletim Econômico. Lisboa: Banco de Portugal - Departamento de Estudos Econômicos, 2013. p. 13-16.

PEREIRA, Manuel Henrique de Freitas. Os Incentivos Fiscais e o Financiamento do Investimento Privado, em influência da fiscalidade na forma de financiamento das 
empresas. Relatório do Grupo de Trabalho constituído pelo Despacho nº130/97-XIII do Ministro da Finanças - Cadernos de Ciência e Técnica Fiscal, Lisboa: Centro de Estudos Fiscais, 1998.

PORTUGAL. Decreto Lei $\mathbf{n}^{0}$ 118, de 15 de dezembro de 2011. Aprova e Institui a Lei orgânica da Autoridade Tributária e Aduaneira. Disponível em: <http://www.pgdlisboa.pt/leis/lei_mostra_articulado.php?nid=1578\&tabela=leis $>$. Acesso em: 04 abril 2019.

PORTUGAL. Decreto Lei $\mathbf{n}^{\circ}$ 215, de 01 de julho de 1989. Institui o Estatuto de Benefícios Fiscais de Portugal. Disponível em: <https://info.portaldasfinancas.gov.pt/pt/informacao_fiscal/codigos_tributarios/bf_rep/index_ ebf.htm>. Acesso em: 04 Março 2019.

PORTUGAL. Decreto Lei $\mathbf{n}^{\mathbf{0}}$ 73, de 03 de setembro de 2013. Estabelece o Regime Financeiro das Autarquias locais e das Entidades Intermunicipais. Disponível em: <http://www.pgdlisboa.pt/leis/lei_mostra_articulado.php?artigo_id=1989A0085\&nid=1989\&t abela=leis\&pagina $=1 \&$ ficha $=1 \&$ nversao $=>$. Acesso em: 01 fev. 2016.

PORTUGAL. Lei 64-B, de 30 de Dezembro de 2011. Dispõe sobre o orçamento de Estado para 2012. Disponível em: <https://dre.pt/pesquisa/-/search/243769/details/maximized>. Acesso em: 12 de março de 2019.

PORTUGAL. Lei n. ${ }^{\circ}$ 20, de 14 de Maio de 2012. Dispõe sobre o orçamento retificativo do ano de 2012. Disponível em: <https://dre.pt/pesquisa/-/search/552023/details/maximized>. Acesso em: 12 de março de 2019.

TRIBUNAL DE CONTAS DE PORTUGAL - TCP. Auditoria à Qualificação da Despesa Fiscal. Relatório no 19/2014 - 2ª Secção. Lisboa: Departamento de Auditoria II, 2014.

WIPO; INSEAD; CORNELL UNIVERSTY. Global Innovation Index. Disponível em: $<$ https://www.globalinnovationindex.org/analysis-indicator >. Acessado em 03/07/2019. 